\title{
Karakteristik Briket Biomassa dengan Variasi Geometri dan Jenis Bahan Baku yang Berbeda
}

\section{Characteristics of Biomass Brickets with Different Geometry Variations and Types of Raw Material}

\author{
I Putu Dharma Putra Ritzada, Ni Luh Yulianti*, Ida Bagus Putu Gunadnya \\ Program Studi Teknik Pertanian dan Biosistem, Fakultas Teknologi Pertanian, Universitas Udayana, Badung, \\ Bali, Indonesia \\ e-mail: yulianti@unud.ac.id
}

\begin{abstract}
Abstrak
Penelitian ini bertujuan untuk menganalisa karakteristik briket biomassa dengan variasi geometri dan jenis bahan baku briket biomassa yang berbeda dan menentukan perlakuan manakah yang menghasilkan briket dengan kualitas yang paling baik. Penelitian ini menggunakan RAK (Rancangan Acak Kelompok) factorial menggunakan 2 faktorial dan 3 kali ulangan. Faktor pertama adalah jenis bahan baku (A) yang terdiri dari tiga taraf yaitu bambu tabah (A1), sekam padi (A2) dan campuran bambu tabah dan sekam padi (A3). Faktor kedua yaitu bentuk geometri briket (B) yang terdiri dari dua taraf yaitu balok (B1) dan silinder (B2). Seluruh perlakuan diulang sebanyak 3 kali sehingga didapatkan 18 data pengamatan. Data yang diperoleh dianalisis dengan sidik ragam dan apabila terdapat pengaruh perlakuan yang signifikan, lalu dilanjutkan dengan uji BNT terhadap ratarata perlakuan. Hasil penelitian menunjukan bahwa interaksi antar perlakuan jenis bahan baku dan bentuk geometri memberikan pengaruh yang signifikan terhadap parameter mutu briket yang dihasilkan. Perlakuan briket yang dibuat dari arang sekam padi dengan bentuk silinder (A2B2) merupakan perlakuan yang menghasilkan briket dengan kualitas paling baik dengan nilai kadar air sebesar 2,64\% bb, kadar abu sebesar $6,60 \%$, laju pembakaran sebesar 73,16 (gr/menit) dan volatille matter sebesar $13,86 \%$.
\end{abstract}

Kata Kunci: bambu tabah, sekam padi, bentuk geometri, briket biomasa

Abstract

This study aims to analyze the characteristics of biomass briquettes with different geometry variations and types of biomass briquette raw materials and determine which treatment produces the best quality briquettes. This research uses block design (RAK) using 2 factorials and 3 replications. The first factor is the type of raw material (A) which consists of three levels, namely tabah bamboo (A1), rice husk (A2) and a mixture of tabah bamboo and rice husk (A3). The second factor is the geometric shape of the briquette (B) which consists of two levels, namely beams (B1) and cylinders (B2). All treatments were repeated 3 times in order to obtain 18 observational data. The data obtained were analyzed by means of variance and if there was a significant treatment effect, then it was followed by the BNT test on the average treatment. The results showed that the interaction between treatments. Types of raw materials and geometric shapes had a significant effect on the quality parameters of the resulting briquettes. The treatment of briquettes made from rice husks in a cylindrical shape (A2B2) is a treatment that produces the best quality briquettes with a moisture content value of $2.64 \%$ bb.ash content was $6.60 \%$, combustion rate was 73.16 (gr/minute) and volatile matter was $13.86 \%$.

Keywords: tabah bamboo, rice husk, geometric shape

\section{PENDAHULUAN}

Masalah energi tidak lepas dari pola hidup manusia. Pertumbuhan total penduduk, kemajuan kebiasaan hidup manusia dan menjadi industri yang berkembang memungkinkan keinginan agar kebutuhan energi selalu naik, adapun ketersediaaan cadangan energi menjadi sedikit (Taufik \& Fenni,
2015). Hal ini mengakibatkan naiknya harga jual bahan bakar minyak di Indonesia, oleh karena diperlukan bahan alternatif yang efisien dan ramah lingkungan guna menggantikan bahan bakar untuk industri kecil dan rumah tangga. Diantaranya perkembangan energi baru dan terbarukan yaitu energi alternative tersebut berbahan biomassa guna dikembangkan lebih lanjut menjadi bahan bakar 
padat yaitu briket (Hastiawan et al., 2018). Briket adalah bahan bakar berbentuk padat dan terbuat dari sisa-sisa bahan organik (Kurdiawan et al., 2013). Briket dipastikan guna diproduksi secara masal dengan jangka waktu yang singkat, berhubung teknologi dan peralatan yang dipakai relatif mudah. Pembuatan briket arang umumnya menggunakan limbah biomassa seperti jerami, serbuk gergaji, atau beberapa cangkang biomassa antara lain kopi, coklat, kemiri serta jagung, ketela dan limbah jarak pagar (Setiani et al., 2019). Pada proses pelepasan massa atau pengarangan dari hasil penelitian ini menggunakan teknologi pyrolisis yakni dilakukan dengan cara dekomposisi thermal bahan organik dengan minim oksigen, seperti bahan utama organik ini agar mengalami pemecahan struktur kimia menjadi fase gas dengan meninggalkan karbon sebagai residu (Sudding \& Jamaluddin, 2015). Karbon dan arang yang diperoleh lalu ditumbuk, diayak kemudian ditambahkan bahan perekat seperti gel amilum, lalu dipadatkan lalu dicetak selanjutnya dikeringkan sehingga hasilnya menjadi briket arang. Berdasarkan beberapa hasil penelitian yang dikemukakan, diketahui bahwa selain bahan baku pembuatan briket, geometri briket juga mempengaruhi kualitas laju pembakaran dan nilai kalor yang dihasilkan.

Selain sekam yang sudah banyak digunakan sebagai bahan baku briket, bambu juga dapat dijadikan bahan baku dalam pembuatan briket. Hal ini dikarenakan bambu memiliki ciri-ciri kadar karbon yang tepat dan abu yang sedikit, situasi ini bisa mengakibatkan kerapatan massa akan lebih besar sehingga rata-rata nilai hasil uji masih dibawah standard tersebut (Ihsan, 2019). Pemanfaatan bambu menjadi bahan baku briket memiliki kelebihan diantaranya adalah kandungan lignin yang dimiliki bambu cukup besar yaitu sebesar $22,91 \%$ dan selulosa yaitu sebesar $44,94 \%$ salah satu jenis bambu yang dapat dijadikan bahan baku briket adalah bambu tabah (Kencana et al., 2012). Sejauh ini penelitian tentang briket biomassa berbahan baku bambu khususnya jenis bambu tabah dan campuran bambu tabah dengan sekam dengan variasi bentuk geometri belum dijumpai. Hal ini Sejalan dengan peneliti guna untuk melakukan kajian lebih dalam tentang karakteristik briket biomassa dengan variasi geometri dan jenis bahan baku briket biomassa yang berbeda sehingga akan diketahui perlakuan manakah yang menghasilkan briket dengan kualitas yang paling baik.

\section{METODE PENELITIAN}

\section{Tempat dan Waktu Penelitian}

Penelitian dilakukan di Laboratorium Pasca panen dan Laboratorium Rekayasa Proses dan Pengendalian Mutu Gedung Agrokomplek Fakultas Teknologi Pertanian Universitas Udayana. Penelitian ini dilaksanakan pada bulan Juli - Agustus 2020.

\section{Alat Dan Bahan}

Alat yang dipakai pada penelitian ini yaitu: alat furnace (merk Barnstead/Thermolyne type 47900), timbangan analitik (merk AND GF-300), cawan porselin, kompor listrik (merk maspion S-301), kompor gas portable (krischef), blender (merk panasonic), desikator, ayakan ukuran $40 \mathrm{mesh}$, alat kempa (alat press ban), wadah plastik, oven (Labo DO 255), cawan aluminium, alat tumbuk kayu, dan cetakan briket.

Bahan yang dipakai pada penelitian ini antara lain bambu tabah (Gegantochloa nigrociliata BUSEKURZ) yang berusia 4 tahun dan sudah dipotong dengan ukuran panjang $5 \mathrm{~cm}$ dan berdiameter $3 \mathrm{~cm}$ yang didapatkan di Desa Padangan Kecamatan Pupuan Kabupaten Tabanan. Bahan lain yang digunakan adalah sekam padi yang didapatkan dari penggilingan beras, Desa Buduk, Kabupaten Badung, dengan tambahan bahan perekat berupa tepung kanji (merk rose brand) dan air.

\section{Rancangan Percobaan}

Penelitian ini menggunakan Rancangan Acak Kelompok dengan pola percobaan faktorial 2 faktor Perlakuan A (jenis bahan baku) yang terdiri dari tiga taraf yaitu arang bambu tabah (A1), arang sekam padi (A2) dan campuran arang bambu tabah dan arang sekam padi (A3). Perlakuan B (jenis bentuk geometri) yang terdiri dari dua taraf yaitu balok (B1) dan silinder (B2):

1. $\mathrm{A} 1 \mathrm{~B} 1=$ Arang bambu tabah $(100 \%)$ dibentuk balok (volume $18 \mathrm{~cm}^{3}$ ) berdimensi panjang $3 \mathrm{~cm}$, lebar $2 \mathrm{~cm}$, tinggi $3 \mathrm{~cm}$.

2. $\mathrm{A} 2 \mathrm{~B} 1=$ Arang sekam padi $(100 \%)$ dibentuk balok (volume $18 \mathrm{~cm}^{3}$ ) berdimensi panjang 3 $\mathrm{cm}$, lebar $2 \mathrm{~cm}$, tinggi $3 \mathrm{~cm}$.

3. $\mathrm{A} 3 \mathrm{~B} 1=$ Arang bambu tabah $(50 \%)+$ Arang sekam padi (50\%) dibentuk balok (volume 18 $\mathrm{cm}^{3}$ ) berdimensi panjang $3 \mathrm{~cm}$, lebar $2 \mathrm{~cm}$, tinggi $3 \mathrm{~cm}$.

4. $\mathrm{A} 1 \mathrm{~B} 2=$ Arang bambu tabah $(100 \%)$ dibentuk silinder (volume $18 \mathrm{~cm}^{3}$ ) berjarijari $1,7 \mathrm{~cm}$ dengan tinggi $2 \mathrm{~cm}$. 
5. $\mathrm{A} 2 \mathrm{~B} 2=$ Arang sekam padi (100\%) dibentuk silinder (volume $18 \mathrm{~cm}^{3}$ ) berjari-jari $1,7 \mathrm{~cm}$ dengan tinggi $2 \mathrm{~cm}$.

6. $\mathrm{A} 3 \mathrm{~B} 2=$ Arang bambu tabah $(50 \%)+$ Arang sekam padi $(50 \%)$ dibentuk silinder (volume $18 \mathrm{~cm}^{3}$ ) berjari-jari $1,7 \mathrm{~cm}$ dengan tinggi 2 $\mathrm{cm}$.

Semua perlakuan diulang 3 kali agar didapatkan 18 data pengamatan. Data yang didapat dianalisis menggunakan sidik ragam jika terdapat pengaruh perlakuan yang signifikan, akan dilanjutkan dengan uji BNT terhadap rata-rata perlakuan.

\section{Pelaksanaan Penelitian}

\section{Proses pengarangan/Pirolisis}

Penelitian dimulai dengan melakukan pemotongan batang bambu dengan ukuran panjang $5 \mathrm{~cm}$, kemudian dilakukan proses pengarangan pada bahan baku tersebut dengan menggunakan cawan porselin besar. Demikian juga sekam padi yang digunakan adalah sekam yang sudah kering. Dan selanjutnya, bambu dan sekam padi dimasukan kedalam alat furnace (merk Barnstead/Thermolyne type 47900) dengan mengatur suhu pembakaran mencapai suhu $300^{\circ} \mathrm{C}$ yang dibakar selama $1 \mathrm{jam}$. Hasil dari proses ini berupa bioarang yang selanjutnya ditumbuk menggunakan alat tumbuk berupa lesung kayu sampai menjadi serbuk. Setelah bahan baku menjadi serbuk, maka semua bahan diayak untuk menghasilkan butiran arang halus yang seragam dengan menggunakan ayakan berukuran 40 mesh.

\section{Pembuatan perekat tepung kanji}

Bahan yang digunakan untuk pembuatan perekat tepung kanji (merk rose brand) yaitu tepung kanji dan air dengan perbandingan 1:1. Proses pengolahan dimulai dengan menggambungkan tepung kanji dan air yang dituangkan di atas panci. Lalu dipanaskan di atas kompor yang menyala, lalu diaduk hingga merata, mengental, dan berwarna keputihan.

\section{Proses pencampuran arang dan perekat}

Hasil serbuk arang bambu dan serbuk arang sekam padi yang sudah ditumbuk dan ditimbang masingmasing dengan berat 100 gram. Selanjutnya, dicampur dengan perekat kanji (merk rose brand) seberat 15gram kemudian diaduk sampai merata sehingga menjadi adonan.

\section{Pencetakan}

Campuran bahan baku dan perekat dimasukan kedalam alat pencetak briket sesuai perlakuan yaitu yang berbentuk balok dengan volume $18 \mathrm{~cm}^{3}$ berdimensi panjang $3 \mathrm{~cm}$, lebar $2 \mathrm{~cm}$, tinggi $3 \mathrm{~cm}$, dan berbentuk silinder dengan volume $18 \mathrm{~cm}^{3}$ berjari-jari
1,7 $\mathrm{cm}$ dengan tinggi $2 \mathrm{~cm}$. Kemudian dikempa menggunakan alat kempa press ban selama 3 menit sampai kondisi briket arang menjadi padat.

\section{Pengeringan}

Briket dikeluarkan dari cetakan dan diangin-anginkan diudara terbuka selama 24 jam, setelah itu dikeringkan didalam oven menggunakan suhu $105^{\circ} \mathrm{C}$ selama 4 jam.

\section{Pengujian kualitas briket}

Selanjutnya briket arang yang diperoleh maka dianalisis kadar air, kadar abu, laju pembakaran dan volatile matter.

\section{Parameter yang Diamati Kadar Air}

Pengujian kadar air dapat mengetahui sifat higroskopis briket (Patandung, 2017).Pengukuran kadar air dilakukan untuk 18 sampel yang disediakan kedalam cawan seberat 3 gram, dan diperoleh berat awal (gram). Briket setelah ditimbang diletakan kedalam oven dengan suhu $105^{\circ} \mathrm{C}$ selama 1x24 jam mendapatkan bobot konstan. Setelah dioven didinginkan memakai desikator selama 10 menit, lalu ditimbang berat akhir (gram). Perhitungan kadar air diperhitungkan seperti dibawah ini (Nadkarni, 2007) :

$$
\begin{aligned}
& \mathrm{M}(\% \mathrm{bb})=\frac{w a-w b}{w a} 100 \% \text {. } \\
& \text { Keterangan: } \quad \mathrm{M}=\text { Kadar air (\%) } \\
& \mathrm{Wa}=\text { berat awal }(\mathrm{g}) \\
& \mathrm{Wb}=\text { berat akhir }(\mathrm{g})
\end{aligned}
$$

\section{Kadar Abu}

Pengujian kadar abu dijalankan dengan cara cawan porselin yang sudah dibersihkan dimasukan ke dalam oven selama 1 jam pada suhu $105^{\circ} \mathrm{C}$, timbang 3 gram sampel ke dalam cawan porselin, bakar menggunakan kompor listrik sebelum dimasukan ke furnace sehingga asapnya hilang, masukkan sample ke dalam furnace pada suhu $600-800^{\circ} \mathrm{C}$ selama 3 jam sehingga menjadi abu, dinginkan cawan dan isinya ke dalam desikator selama 15 menit lalu ditimbang untuk mendapatkan berat abu, kadar abu (\%) perhitungan dengan rumus :

Kadar Abu $=\frac{\text { massa sisa abu }(\mathrm{g})}{\text { massa kering briket }(\mathrm{g})} \times 100 \%$........(2)

\section{Laju Pembakaran}

Pengujian laju pembakaran ini agar diketahui laju briket dari membara sampai menjadi abu. Menurut Sudding \& Jamaluddin, (2015) bahwa ciri pembakaran pada briket, dijalankan sebagai tolak ukur guna pengolahan bahan bakar yang sederhana dalam pemakaiannya. Disediakan sampel dan ditimbang bobot briket sebelum dilakukan percobaan laju pembakaran. Selanjutnya, disiapkan kayu yang sudah di nyalakan apinya lalu briket disimpan diatas 
kawat kasa. Ketika briket sudah membara, kayu yang terbakar cepat dihindarkan dan lama nyalanya briket diukur dengan stopwatch agar baranya padam. Persamaan yang dipakai guna mengetahui laju pembakaran yakni:

Laju pembakaran $\left(\mathrm{L}_{\mathrm{p}}\right)=\frac{m}{t}(\mathrm{gr} / \mathrm{menit})$

Keterangan: $\quad$ Lp $=$ Laju pembakaran (gr/menit)

$\mathrm{M}=$ Bobot sampel (gr)

$\mathrm{t}=$ Waktu pembakaran (menit)

\section{Volatille Matter}

Pengujian volatille matter dilakukan dengan cara cawan porselin ditimbang lebih awal massanya ke dalam cawan porselin diisi menggunakan sampel sebanyak 3 gram kemudian ditimbang. Setelah itu pemanasan pada alat furnace dengan suhu $750^{\circ} \mathrm{C}$ selama 7 menit. Dinginkan dengan desikator selama $1 / 2$ jam kemudian ditimbang, kadar zat menguap (\%) diperhitungkan dengan persamaan:

Kadar volatile $(\%)=\frac{\text { Wo- } \mathrm{W}}{\text { Wo }} \times 100 \%$

$$
\begin{array}{ll}
\text { Keterangan: } & \text { Wo }=\text { kadar sampel awal }(\mathrm{g}) \\
& \mathrm{W}=\text { berat sampel akhir }
\end{array}
$$

\section{Analisis Data}

Semua perlakuan diulang 3 kali agar didapatkan 18 data pengamatan. Data yang didapat dianalisis menggunakan sidik ragam jika terdapat pengaruh perlakuan secara signifikan, akan dilanjutkan dengan uji BNT terhadap rata-rata perlakuan. Perlakuan terbaik dipilih dari perlakuan yang menghasilkan nilai paling mendekati standar SNI.

\section{HASIL DAN PEMBAHASAN}

\section{Kadar Air}

Kadar Air adalah suatu parameter yang diperlukan guna menentukan kualitas briket yang diperoleh. Hasil analisis keragaman memperlihatkan bahwa interaksi bahan baku (faktor A) dan bentuk geometri (faktor B) berpengaruh signifikan terhadap parameter kadar air. Pengaruh interaksi bahan baku dan bentuk geometri kadar air briket bioarang tampak pada Gambar 1 dan Tabel 1.

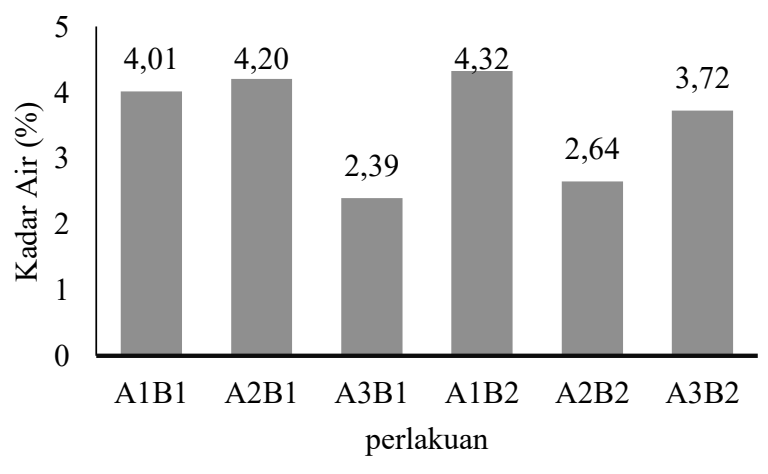

Gambar 1. Perlakuan hasil analisis uji kadar air (\%bb)

Tabel 1. Nilai kadar air $(\% \mathrm{bb})$ berdasarkan perlakuan

\begin{tabular}{|c|c|c|}
\hline \multirow[b]{2}{*}{ BAHAN BAKU } & \multicolumn{2}{|c|}{ BENTUK GEOMETRI } \\
\hline & Balok (B1) & $\begin{array}{l}\text { Silinder } \\
\text { (B2) }\end{array}$ \\
\hline $\begin{array}{l}\text { Arang bambu } \\
\text { tabah (A1) }\end{array}$ & $4,01 b c$ & $4,32 c$ \\
\hline $\begin{array}{l}\text { Arang sekam } \\
\text { padi (A2) }\end{array}$ & $4,20 c$ & $2,64 a$ \\
\hline $\begin{array}{l}\text { Arang bambu } \\
\text { tabah dan Arang } \\
\text { sekam padi (A3) }\end{array}$ & $2,39 a$ & $3,72 b$ \\
\hline
\end{tabular}
bentuk geometri dan jenis bahan baku

Pada Gambar 1 dan Tabel 1. Menunjukan pada interaksi bahan baku dan bentuk geometri sangat berpengaruh signifikan pada kadar air briket yang dihasilkan. Selanjutnya pada data yang dihasilkan, diketahui bahwa kadar air dari tiap-tiap perlakuan sudah memenuhi standar SNI, dimana kadar air terendah diperoleh pada perlakuan A3B1 (arang bambu tabah dan arang sekam padi bentuk balok) yaitu sebesar $2,39 \%$ bb. Selanjutnya perlakuan ini didapatkan pengaruh yang tidak berbeda nyata dengan perlakuan A2B2 (arang sekam padi bentuk silinder), namun mendapatkan pengaruh yang berbeda nyata dibandingkan menggunakan perlakuan lainnya. Rendahnya nilai kadar air pada perlakuan briket yang berbahan baku arang sekam padi baik pada briket yang berbentuk silinder maupun berbentuk balok adalah dikarenakan bahan baku tersebut memiliki nilai masa jenis yang lebih rendah bila dibandingkan briket dengan bahan baku lainnya. Dapat mempengaruhi susunan rongga antar partikel didalam bahan baku, dimana perlakuan A2B2 (arang sekam padi bentuk silinder) yaitu bahan baku arang sekam memiliki rongga antar partikel yang lebih besar dibandingkan bahan lainnya dimana kondisi ini akan mempermudah uap air tersimpan didalamnya untuk keluar dari dalam jaringan menuju lingkungan saat proses pengeringan. Menurut penelitian yang dilakukan oleh Suheryanto et al.,(2013) yang disampaikan bahwa semakin meningkat kerapatan sehingga rongga-rongga antar partikel arang juga akan semakin rapat sehingga tidak terdapat atau sangat sedikit sekali jumlah celah atau ruang kosong didalamnya. Kadar air briket berbahan baku sekam memiliki nilai kadar air lebih rendah dibandingkan bambu, tempurung kelapa dan tongkol jagung pada rentang waktu pengarangan 60 menit (Taufik \& Fenni, 2015). Selanjutnya dari penelitian tersebut juga diketahui bahwa kadar air briket berbahan baku 
sekam padi adalah sebesar 3,4\% bb sementara bambu memiliki kadar air sebesar 5,25\% bb. Menurut penelitian Almu et al., (2014) menyatakan bahwa kadar air yang tinggi diduga terdapat jumlah pori-pori yang masih berkecukupan sehingga mampu menyerap air lebih banyak. Selain itu, dari penelitian yang sama diketahui bahwa bentuk geometri juga mempengaruhi susunan rongga antar partikel sedangkan berat briket mempengaruhi banyaknya rongga antar partikel pontensi ini dapat mempengaruhi uap air tersimpan didalamnya. Jumlah pori-pori yang banyak dan adanya kandungan unsurunsur kimia, yakni selulosa, lignin sehingga dapat mempengaruhi mempunyai kandungan nilai kadar air pada briket (Purnomo et al., 2015).

Perlakuan dengan kadar air yang rendah merupakan perlakuan yang diharapkan dalam pembuatan briket, hal ini disebabkan briket dengan kadar air tersebut rendah relative memiliki nilai kalor ini lebih baik dibandingkan briket dengan kadar air yang lebih meningkat. Nilai kadar air pada briket dapat memberikan pengaruh pada saat digunakan sebagai energi, dimana nilai kadar air yang tinggi dapat menyebabkan timbulnya permasalahan disebabkan oleh panas yang ada dalam briket tersebut akan dimanfaatkan untuk mengeluarkan air terlebih awal, dan selanjutnya dimanfaatkan sebagai panas pembakaran. Hal ini di karenakan kadar air dalam briket yakni faktor pokok yang dapat di pertimbangkan guna untuk bahan baku energi karena bisa mempengaruhi sifat fungsional briket secara menyeluruh (Elsaprike et al., 2018). Menurut penelitan yang dilakukan oleh Susanto \& Yanto, (2013) didapatkan bahwa nilai kadar air pada bahan baku rata - rata sebesar $8,15 \%$ bb, sesuai dengan standar yang ditetapkan jepang yaitu 6-8\% bb serta indonesia $7,57 \%$ bb. Briket dengan nilai kadar air rendah akan menghasilkan nilai kalor tinggi, dan sebaliknya briket dengan kadar air tinggi akan menghasilkan nilai kalornya rendah. Hal ini dikarenakan panas yang diperoleh akan dapat untuk menguapkan air terlebih dahulu, kemudian panas yang dihasilkan selanjutnya akan digunakan sebagai pembakaran. Maka bisa disimpulkan bahwa diketahui hubungan antara kadar air dengan nilai kalor.

\section{Kadar Abu}

Kadar abu adalah residu yang diperoleh pada hasil pembakaran yang tidak mempunyai kadar karbon lagi. Kandungan zat anorganik sehingga tidak dapat terbakar sampai tertinggal dan menjadi abu. Selanjutnya hasil analisis keragaman memperlihatkan bahwa interaksi antar perlakuan yaitu jenis bahan baku (faktor A) dan bentuk geometri (faktor B) mendapatkan pengaruh signifikan terhadap kadar abu yang dihasilkan. Pengaruh interaksi bahan baku dan bentuk geometri kadar abu briket bioarang dapat dilihat pada Gambar 2 dan Tabel 2.

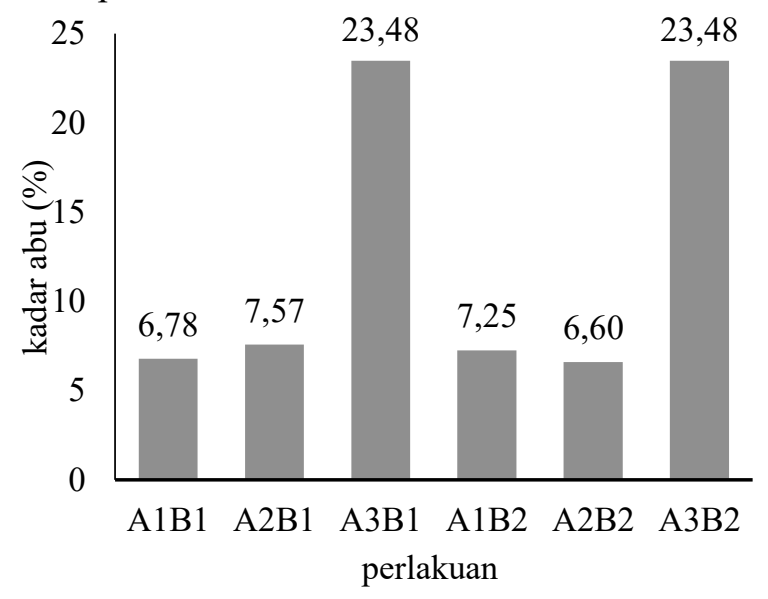

Gambar 2. Perlakuan hasil analisis uji kadar abu $(\%)$.

Tabel 2. Nilai kadar abu (\%) berdasarkan perlakuan bentuk geometri dan jenis bahan baku

\begin{tabular}{clc}
\hline \multirow{3}{*}{ BAHAN BAKU } & \multicolumn{2}{l}{ BENTUK GEOMETRI } \\
& Balok (B1) & Silinder (B2) \\
\hline $\begin{array}{c}\text { Arang bambu tabah } \\
\text { (A1) }\end{array}$ & $6,78 a b$ & $7,25 ~ b c$ \\
$\begin{array}{c}\text { Arang sekam padi } \\
\text { (A2) }\end{array}$ & $7,57 \mathrm{c}$ & $6,60 \mathrm{a}$ \\
$\begin{array}{c}\text { Arang bambu tabah } \\
\text { dan Arang sekam } \\
\text { padi (A3) }\end{array}$ & $23,48 d$ & $23,48 d$ \\
\hline $\begin{array}{c}\text { Keterangan: Huruf yang beda dibelakang nilai rata-rata } \\
\text { menunjukan nilai berbeda nyata }(P>0,05)\end{array}$
\end{tabular}

Pada Gambar 2 dan Tabel 2. menunjukan pada kadar abu yang di peroleh pada beberapa perlakuan sudah memenuhi syarat SNI dibawah $8 \%$ yakni perlakuan A1B1 (arang bambu tabah bentuk balok), A2B1 (arang sekam padi bentuk balok), A1B2 (arang bambu tabah bentuk silinder) dan A2B2 (arang sekam padi bentuk silinder). Selanjutnya beberapa perlakuan yang melebihi syarat SNI yakni diatas $8 \%$ diantaranya perlakuan A3B1 (arang bambu tabah dan arang sekam padi bentuk balok) dan perlakuan A3B2 (arang bambu tabah dan arang sekam padi bentuk silinder). Tingginya nilai kadar abu yang terdapat pada perlakuan briket yang bebahan baku campuran arang sekam dan arang bambu diduga akibat dari jumlah pengotor yang terkandung dalam bahan baku cukup tinggi, Hal ini menyebabkan kandungan mineral yang tertinggal dalam arang sekam dan arang bambu juga meningkat dan pada pengolahannya pembakarannya akan menyisakan abu yang banyak akan sisa dari pembakaran. Hasil dari penelitian yang dilakukan oleh Purnama et al., (2012) yang menyatakan bahwa meningkatnya kadar abu dapat dikarenakan oleh adanya pengotor (impurities) 
berupa mineral yang tidak habis terbakar atau teroksidasi oleh oksigen. Selain itu, tingginya kadar abu dapat disebabkan oleh pengotor eksternal yang berasal dari lingkungan pada waktu pengolahan pembuatan briket. Pengotor eksternal dapat diperoleh dari efisiensi panas pada alat pirolisis yang kurang tepat (Ristianingsih et al., 2015). Selanjutnya dari data tersebut juga diketahui bahwa, kadar abu yang terendah diperoleh pada perlakuan A2B2 (arang sekam padi bentuk silinder) yaitu sebesar 6,60\%. Selanjutnya perlakuan ini memperoleh efek yang tidak berbeda nyata dengan perlakuan A3B2 (arang bambu tabah dan arang sekam padi bentuk silinder), namun memberikan efek yang berbeda nyata dibandingkan dengan perlakuan lainnya.

Kadar abu yang rendah pada perlakuan A2B2 (arang sekam padi bentuk silinder) kemungkinan diakibatkan oleh kadar air yang rendah pada perlakuan tersebut. Abu adalah komponen yang tersisa pada suatu proses pembakaran dimana unsur karbon sudah tidak ditemukan di dalamnya. Unsur utama abu merupakan silika dan berpengaruh kurang tepat pada nilai kalor yang diperoleh. Sehingga, makin meningkat kadar abu berbanding terbalik dengan menurunnya kualitas briket yang dihasilkan disebabkan kualitas kadar abu dapat meningkat akan menyebabkan penurunan pada nilai kalor (Susanto \& Yanto, 2013). Penelitian yang dilaksanakan oleh Purnomo et al.,(2015) mengungkapkan bahwa penambahan kosentrasi arang maka menyebabkan nilai kadar abu mengalami kenaikan dan penurunan kosentrasi arang maka menyebabkan nilai kadar abu briket mengalami penurunan. Karbonasi secara konvensional menghasilkan dari analisis kadar abu yang meningkat dibandingkan karbonisasi pada suhu $500^{\circ} \mathrm{C}$ (Latifa, 2015). Dari penelitian yang didapatkan oleh Hendra\& Winarmi, (2003) yang mengungkapkan bahwa perbedaan jenis bahan pokok dan bentuk geometri mempengaruhi Kadar Abu briket arang yang diperoleh. Menurut penelitian yang dilakukan oleh Hendra, (2007) mengungkapkan bahwa faktor ciri bahan pokok sangat mempengaruhi kadar abu briket yang dihasilkan dengan kadar abu briket. Menurut penelitian yang dilakukan oleh Ismanto \& Martono,(2012) menyatakan bahwa kadar abu bisa juga dapat dikarenakan oleh penggabungan bahan perekat dan bahan pokok yang tidak sesuai maka pada pengolahan pembakaran bahan perekat terbakar menjadi abu.

\section{Laju Pembakaran}

Laju pembakaran merupakan contoh berkurangnya bobot per satuan waktu selama pembakaran. diperoleh analisis keragaman memperlihatkan adanya interaksi antara bahan baku (faktor A) dan bentuk geometri (faktor B) yang berpengaruh nyata terhadap laju pembakaran. Pengaruh interaksi bahan baku dan bentuk geometri laju pembakaran briket bioarang dapat dicerminkan sesuai Gambar 3 dan Tabel 3.

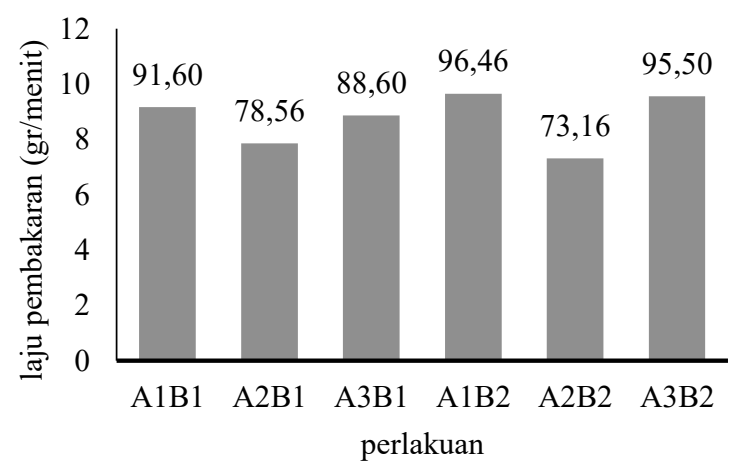
Gambar 3. Perlakuan hasil analisis uji laju
pembakaran (gr/menit).

Tabel 3. Nilai laju pembakaran (gr/menit) berdasarkan perlakuan bentuk geometri dan jenis bahan baku.

\begin{tabular}{llc}
\hline \multirow{2}{*}{ BAHAN BAKU } & \multicolumn{2}{c}{ BENTUK GEOMETRI } \\
& Balok (B1) & Silinder (B2) \\
\hline $\begin{array}{l}\text { Arang bambu tabah } \\
\text { (A1) }\end{array}$ & $91,60 \mathrm{~cd}$ & $96,46 \mathrm{e}$ \\
$\begin{array}{l}\text { Arang sekam padi } \\
\text { (A2) }\end{array}$ & $78,56 \mathrm{~b}$ & $73,16 \mathrm{a}$ \\
$\begin{array}{l}\text { Arang bambu tabah } \\
\text { dan arang sekam }\end{array}$ & $88,60 \mathrm{c}$ & $95,50 \mathrm{de}$ \\
padi (A3) & & \\
$\begin{array}{l}\text { Keterangan: Huruf yang beda dibelakang nilai rata-rata } \\
\text { menunjukan nilai berbeda nyata }(P>0,05) .\end{array}$
\end{tabular}

Pada Gambar 3 dan Tabel 3. Menunjukan bahwa interaksi bahan baku dan bentuk geometri sangat berpengaruh nyata terhadap laju pembakaran. Berdasarkan data yang diperoleh, diketahui bahwa briket untuk semua semua perlakuan mudah terbakar, sehingga belum dapat ketetapan dalam SNI mengenai standarisasi besar laju pembakaran briket. Berdasarkan data diatas didapatkan bahwa laju pembakaran terendah terdapat pada pelakuan A2B2 (arang sekam padi bentuk silinder) yaitu sebesar 73,16 gr/menit. Selanjutnya perlakuan ini memperoleh efek yang tidak berbeda nyata pada perlakuan A2B1 (arang sekam padi bentuk balok), sehingga memperoleh efek yang berbeda nyata dibandingkan dengan perlakuan lainnya. Laju pembakaran yang rendah pada perlakuan ini sejalan dengan kadar air dengan kadar abu yang rendah yang dipdapatkan dalam penelitian ini, dimana dengan nilai kadar air yang rendah memungkinkan briket dapat menghasilkan pembakaran yang semakin cepat. Selanjutnya berdasarkan data diatas diketahui bahwa kemungkinan laju pembakaran dipengaruhi oleh jenis 
bahan baku yang digunakan, hal ini ditunjukan dari jenis arang sekam padi yang menghasilkan laju pembakaran lebih rendah. Hal ini dikarenakan arang sekam padi mempunyai karateristik kadar karbon yang tepat dan abu yang sedikit. Menurut penelitian yang dilakukan oleh Taufik \& Fenni (2015) menyatakan bahwa dengan bentuk geometri yang berbeda ternyata efek pada nilai laju pembakaran yakni disebabkan oleh bentuk geometri pada bahan dipastikan oleh sudut dan garis pembentuknya. Semakin sedikit sudut dan garis yang dibentuk sehingga semakin luas permukaannya, hal ini menyebabkan laju pembakaran dapat semakin cepat disebabkan perambatan udara guna berfungsi untuk energi pada pengolahan pembakaran maka lebih cepat diperoleh, sebaliknya begitu pula (Purwanto \& Sofyan, 2014).

\section{Volatille Matter}

Volatille matter adalah material yang gampang menguap pada arang yang biasanya seperti metana, senyawa hidrokarbon, hidrogen, dan gas yang tidak mudah terbakar seperti karbondioksida dan nitrogen. Hasil dari analisis keragaman memperlihatkan bahwa interaksi bahan baku (faktor A) dan bentuk geometri (faktor B) menghasilkan efek sangat nyata pada kadar zat menguap. Pengaruh interaksi bahan baku dan bentuk geometri pada kadar zat menguap bisa dicerminkan t pada Gambar 4 dan Tabel 4.

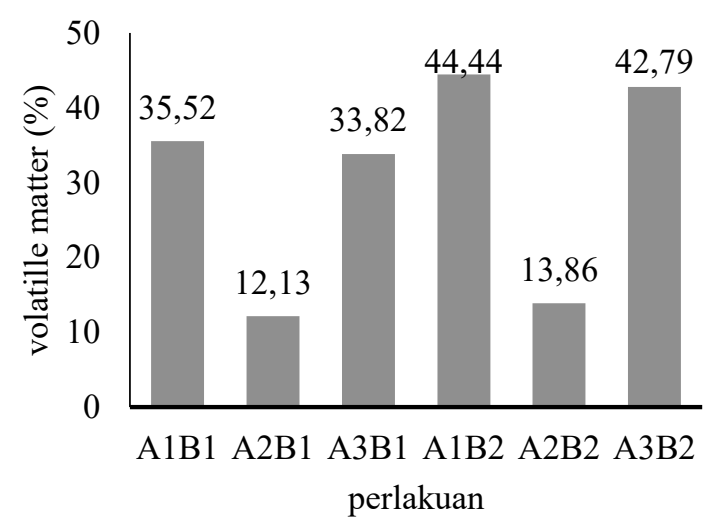

Gambar 4. Perlakuan hasil analisis uji volatille matter $(\%)$.
Tabel 4. Nilai volatille matter (\%) berdasarkan perlakuan bentuk geometri dan jenis bahan baku.

\begin{tabular}{lcc}
\hline \multirow{2}{*}{ BAHAN BAKU } & \multicolumn{2}{c}{ BENTUK GEOMETRI } \\
& Balok (B1) & Silinder (B2) \\
\hline $\begin{array}{l}\text { Arang bambu tabah } \\
\text { (A1) }\end{array}$ & $35,52 b$ & $44,44 c$ \\
Arang sekam padi & $12,13 a$ & $13,86 a$ \\
(A2) & $42,79 c$ \\
$\begin{array}{l}\text { Arang bambu tabah } \\
\text { dan arang sekam }\end{array}$ & $33,82 b$ & \\
padi (A3) & & \\
Keterangan: Huruf yang beda dibelakang nilai rata-rata \\
menunjukan nilai berbeda nyata $(P>0,05)$.
\end{tabular}

Pada Gambar 4 dan Tabel 4. Menampilkan bahwa interaksi bahan baku dan bentuk geometri sangat mempengaruhi nyata pada kadar zat menguap. Berdasarkan data ini diperoleh, diketahui bahwa kadar zat menguap yang diperoleh pada beberapa sudah memenuhi standar SNI yaitu sebesar $\leq 15 \%$ akan tetapi ada beberapa perlakuan yang melebihi standar SNI yang disyaratkan, dimana kadar zat manguap yang terendah diperoleh pada perlakuan A2B1 (arang sekam padi bentuk balok) yaitu sebesar $12,13 \%$. Selanjutnya perlakuan ini memperoleh efek yang tidak berbeda nyata dengan perlakuan A2B2 (arang sekam padi bentuk silinder), namun memperoleh efek yang berbeda nyata dibandingkan dengan perlakuan lainnya. Selanjutnya berdasarkan data diketahui bahwa kemungkinan kadar zat menguap efek dari jenis bahan pokok yang digunakan, hal ini ditunjukan dari arang sekam padi yang menghasilkan kadar zat menguap cenderung rendah, karena sifat sekam padi yang mengalami penyusutan (skrinkage), serta dalam keadaan basah bersifat linear (Lempang, 2016). Perlakuan briket berbahan baku arang sekam dengan bentuk silinder memiliki nilai volatille matter rendah disebabkan karena kandungan volatille matter sangat berperan pada menetapkan ciri pembakaran, menjadi sedikit kandungan volatille matter sehingga menjadi mudah bahan pokok dalam terbakar, sehingga laju pembakaran menjadi tinggi. Selain itu, bentuk geometri briket dan perekat pati pada bentuk cairan untuk bahan perekat memperoleh briket pada kadar zat menguap yang bernilai rendah (Sudding \& Jamaluddin, 2015). Pada penelitian ini diungkapkan oleh Surest \& Afif, (2011) yang berbicara bahwa nilai kadar zat menguap briket yang meningkat diduga memiliki nilai fuel ratio rendah yang disebakan oleh total karbon pada briket tersebut banyak yang terbakar. Kadar zat menguap yang meningkat agar memperlancar penyalaan dimana tinggi rendah kadar zat menguap dalam briket diduga dikarenakan oleh keutuhan pengolahan karbonisasi dan dapat dipengaruhi pada waktu dan suhu. Semakin meningkat suhu maupun waktu pengarangan dapat 
semakin meningkat zat menguap yang terbang sehingga agar dalam saat percobaan zat menguap dapat menghasilkan zat menguap yang rendah. Dan semakin meningkat suhu karbonisasi maka bisa berkurangnya kadar zat menguap (Purnomo et al., 2015).

\section{KESIMPULAN DAN SARAN}

\section{Kesimpulan}

bahwa :

Dari data penelitian dapat disimpulkan

1. Hasil penelitian menunjukan bahwa interaksi antar perlakuan jenis bahan baku dan bentuk geometri memperoleh efek yang signifikan pada parameter mutu briket yang didapatkan.

2. Perlakuan briket yang dibuat dari arang sekam padi dengan bentuk silinder (A2B2) merupakan perlakuan yang menghasilkan briket dengan kualitas paling baik pada nilai kadar air sebanyak 2,64\% bb, kadar abu sebesar $6,60 \%$, laju pembakaran sebesar 73,16 (gr/menit) dan volatille matter sebesar $13,86 \%$.

\section{Saran}

1. Dibutuhkan penelitian lebih lanjut pada penggunaan variasi geometri yang berbeda seperti bentuk segitiga dalam pembuatan briket dan menganalisis karakteristik briket biomassa yang dihasilkan.

2. Diperlukan penelitian lebih lanjut dengan bahan baku yang berbeda terhadap karakteristik briket biomassa.

3. Diperlukan penelitian lebih lanjut untuk menguji parameter nilai kalor.

\section{DAFTAR PUSTAKA}

Almu, M. A., Syahrul, S., \& Padang, Y. A. (2014). Analisa Nilai Kalor Dan Laju Pembakaran Pada Briket Campuran Biji Nyamplung (Calophyllm Inophyllum) Dan Abu Sekam Padi.Dinamika Teknik Mesin, 4(2), 117-122. https://doi.org/10.29303/d.v4i2.61

Elsaprike, J., Yahya, R., \& Yuwana, Y. (2018). Pembuatan Arang Dengan Metode Tungku Piloris Double Burner Menggunakan Limbah Kayu Dengan Metode Manduk Di Kecamatan Tebing Tinggi Kabupaten Empat Lawang. Naturalis: Jurnal Penelitian Pengelolaan Sumber Daya Alam Dan Lingkungan, 7(2), 3340. https://doi.org/10.31186/naturalis.7.2.6009

Hastiawan, I., Ernawati, E., Noviyanti, A. R., Eddy,
D. R., \& Yuliyati, Y. B. (2018). Pembuatan briket dari limbah bambu dengan memakai. Dharmakarya: Jurnal Aplikasi Ipteks Untuk Masyarakat, 7(3), 154-156.

Hendra, D. (2007). Pembuatan Briket Arang Dari Campuran Kayu, Bambu, Sabut Kelapa Dan Tempurung Kelapa Sebagai Sumber Energi Alternatif. In Jurnal Penelitian Hasil Hutan (Vol. 25, Issue 3, pp. 242-255). https://doi.org/10.20886/jphh.2007.25.3.242255

Ihsan, (2019). Pengaruh Komposisi Terhadap Karakteristik Briket Kombinasi Arang Tempurung Kelapa Dan Arang Bambu. JFT: Jurnal Fisika Dan Terapannya, 6(1), 89. https://doi.org/10.24252/jft.v6i1.12737

Ismanto, A., \& Martono, D. (2012). ( Physical Properties and Dimentional Stabilization of Several Commercial Bamboo Species ). 30(3), 163-170.

Kencana, P. K. D., Widia, W., \& Antara, N. S. (2012). Praktek Baik Budi Daya Bambu Rebung Tabah (Gigantochloa nigrociliata BUSE-KURZ). 169.

https://bamboeindonesia.files.wordpress.com/2 012/06/budidaya-bambu-rebung-tabah.pdf

Kurdiawan, Y. Z., Erlangga, M., \& Juliastuti, S. R. (2013). Pemanfaatan Limbah Sekam Padi Menjadi Briket Sebagai Sumber Energi Alternatif dengan Proses Karbonisasi dan Nonkarbonisasi. ITS Chemical Engineering, 2(1), 15.

Latifa, A. (2015). Digital Repository Universitas Jember.

http://repository.unej.ac.id/bitstream/handle/12 3456789/65672/Ainul Latifah101810401034.pdf?sequence $=1$

Lempang, M. (2016). Pengawetan Bambu Untuk Barang Kerajinan Dan Mebel Dengan Metode Tangki Terbuka. Info Teknis EBONI, 13(Desember 2016,), 79-92. http://balithutmakassar.org/wpcontent/uploads/2017/11/01_PengawtanBambu-Tangki-Terbuka_InfotekeBoni.pdf

Nadkarni, R. (2007). Guide to ASTM Test Methods for the Analysis of Petroleum Products and Lubricants, 2nd Edition. In Guide to ASTM Test Methods for the Analysis of Petroleum Products and Lubricants, 2nd Edition. https://doi.org/10.1520/mnl44-2nd-eb

Patandung, P. (2017). Pengaruh Jumlah Tepung Kanji Pada Pembuatan Briket Arang Tempurung Pala. Jurnal Penelitian Teknologi Industri, 6(2), 95. https://doi.org/10.33749/jpti.v6i2.3195

Purnama, Chumaidi, A., \& Saleh., A. (2012). Pemanfaatan Limbah Cair CPO Sebagai 
Perekat Pada Pembuatan Briket dari Arang Tandan Kosong Kelapa Sawit.18(45).

Purnomo, R. H., Hower, H., \& Padya, I. R. (2015). Pemanfaatan limbah biomassa untuk briket sebagai energi alternatif. Prosiding Seminar Agroindustri Dan Lokakarya Nasional FKPTTPI, September, 2-3.

Purwanto, J., \& Sofyan, S. (2014). Pengaruh Suhu dan Waktu Pengarangan Terhadap Kualitas Briket Arang dari Limbah Tempurung Kelapa Sawit. Jurnal Litbang Industri, 4(1), 29. https://doi.org/10.24960/jli.v4i1.638.29-38

Ristianingsih, Y., Ulfa, A., \& Syafitri, R. (2015). Karakteristik Briket Bioarang Berbahan Baku Tandan. Jurnal Konversi, 4(2), 16-21.

Setiani, V., Setiawan, A., Dhani, M. R., \& Maulidya, R. D. (2019). Analisis Proximate Briket Tempurung Kelapa dan Ampas Tebu. Jurnal Presipitasi: Media Komunikasi Dan Pengembangan Teknik Lingkungan, 16(2), 91. https://doi.org/10.14710/presipitasi.v16i2.9196

Sudding, \& Jamaluddin. (2015). Pengaruh Jumlah Perekat Kanji terhadap Lama Briket Terbakar menjadi Abu. Jurnal Chemical, 16(1), 27-36.

Suheryanto, D., Susilaning, L., Hastuti, S., Kusumanegara, J., \& Yogyakarta, N. (2013). Pembuatan Arang Bambu (Bamboo Charcoal) Pada Suhu. 2, 51-59.

Surest, A. H., \& Afif, H. (2011). Kayu Dan Tempurung Kelapa Dengan Proses Karbonisasi. 17(8), 29-40.

Susanto, A., \& Yanto, T. (2013). Pembuatan Briket Bioarang Dari Cangkang Dan Tandan Kosong Kelapa Sawit. Jurnal Teknologi Hasil Pertanian, $\quad$ 6(2). https://doi.org/10.20961/jthp.v0i0.13516

Taufik, I., \& Fenni, S. (2015). Efektivitas Bentuk Geometri Dan Berat Briket Bioarang Dari Bambu Terhadap Kualitas Penyalaan Dan Laju Pembakaran. Jurnal Teknik Kimia, 10(1), 8-12. 